\title{
Application of solar energy in various construction industries
}

\author{
Artem Subbotin ${ }^{1}$, Viktoriya Larina ${ }^{1}$,Vasilisa Salmina ${ }^{1}$, and Anastasiya Arzumanyan ${ }^{1, *}$ \\ ${ }^{1}$ Moscow state University of civil Engineering, Yaroslavskoe shosse, 26, Moscow, 129337, Russia
}

\begin{abstract}
This article discusses the use of the sun as an energy source. The most innovative and useful applications for various branches of human activity are presented today, as well as prospects for the development of this technology. Solar panels are used all over the world, and this article offers one of the options for using solar energy. This option can solve many problems of power supply in various remote areas from civilization, providing the most inaccessible places for Central power supply with lighting and video surveillance, allowing continuous monitoring of objects, which will help ensure safety for nature and humans. Video surveillance cameras and lighting powered by solar energy are economical to use, safe for the environment, and easy to install and operate.
\end{abstract}

\section{Introduction}

Reducing the amount of energy consumed by household and industrial equipment, as well as their environmental friendliness and safety for the environment is one of the most important tasks that thousands of scientists and engineers around the world are working to solve. To date, we have developed many ways to make devices less expensive or completely Autonomous. One of the options for supplying the object with electricity is to install a solar battery. These modules can be used far from centralized lines, which makes this method of generating electricity simply necessary in such remote places from civilization, such as railway roads, highways, engineering networks, national parks, mountain ecotropes, etc.

\section{Application experience}

Innovative materials and technologies are being implemented in various areas. One of the most promising developments is the solar-powered wireless video surveillance cameras that do not require connection to the power grid and transmit information via wireless communication channels. Digital technologies allow you to control devices and view videos remotely.

Solar-powered outdoor video surveillance cameras are powered exclusively by solar energy and do not depend on other sources of electricity - they are completely Autonomous. For this purpose, solar panels are used that power the camera and charge the battery. And in

\footnotetext{
${ }^{*}$ Corresponding author: angela-1309.m@yandex.ru
} 
the dark, the system is powered by the battery. On rainy, cloudy days, solar panels continue to generate electricity, since they also work in diffuse daylight.

Poles with surveillance cameras are also equipped with lighting devices that are powered by the same solar battery. In the dark, they will provide security for people and will not stop video surveillance even at night.

These installations will help solve problems such as lighting and monitoring of the area in the absence of communication and centralized power supply.

Autonomous outdoor video surveillance systems use high-quality solar panels to capture direct and scattered sunlight, and convert sunlight into direct current.

The resulting electricity is used to operate the IP camera and charge batteries that store excess electricity generated by the solar panel.

The video surveillance camera can save the captured video to a removable SD card, hard disk, and broadcast the video online via wireless networks

Solar panels are more efficient on clear days, but they can also generate electricity on rainy or cloudy days, as visible light penetrates through rain and clouds. The panels are produced in a water-proof version, so rain and snow are not afraid of it.

If the video surveillance system is installed in areas where the sun is low, cameras with wind generators are used, or combined-a solar panel and a windmill. This solution is also suitable for a rotary zoom camera that can be controlled remotely via a computer program or a mobile phone app.

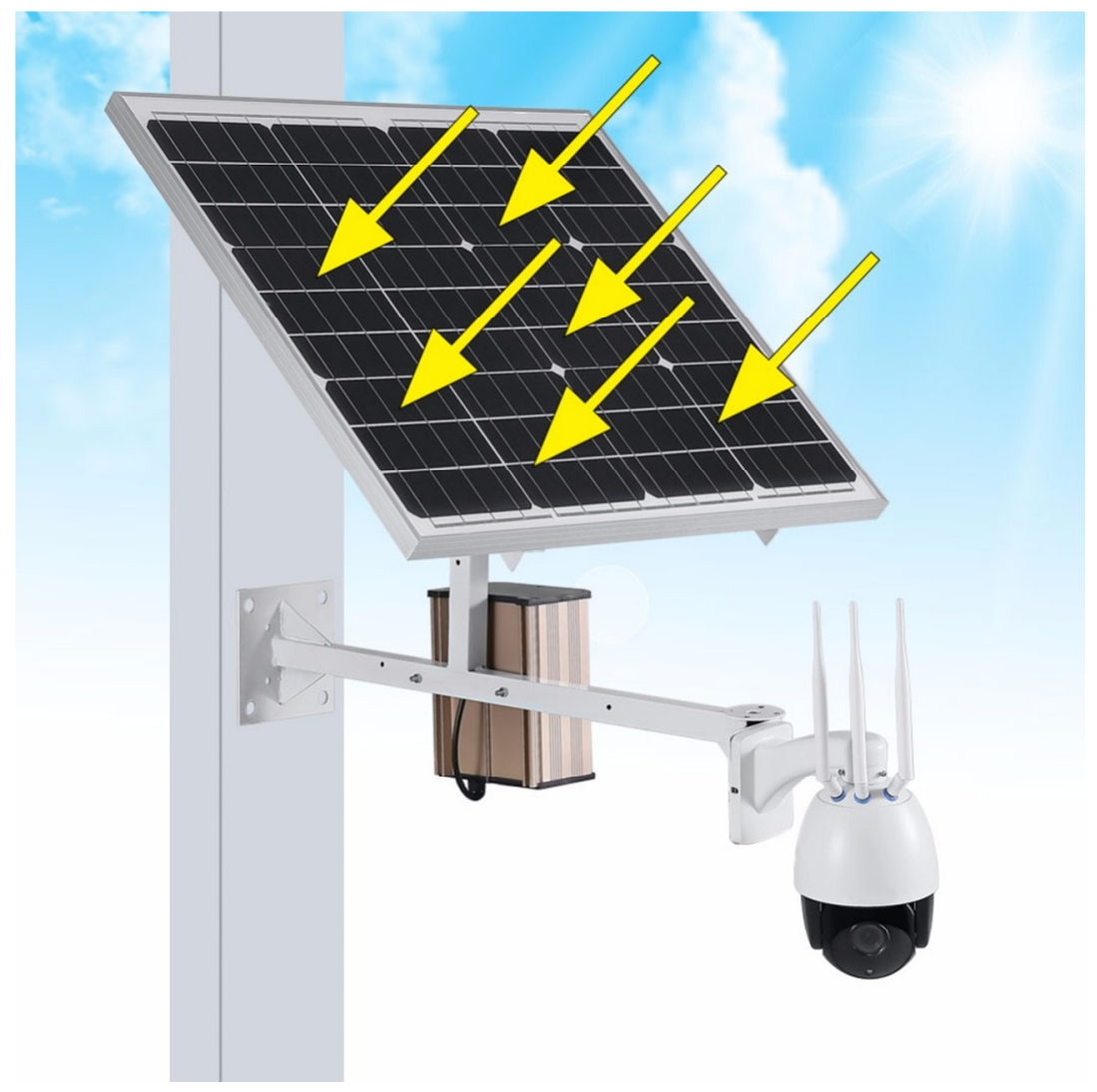

Fig. 1. Solar-powered surveillance camera.

Five advantages of solar-powered outdoor Autonomous cameras, namely: 
1. Flexible location. The presence of a solar battery allows you to install the camera in any place where there is sunlight: in the field, in the mountains, in the country without electricity, on an empty country site, on the highway.

2. Easy to install and move. The set of solar-powered video surveillance system includes everything you need to install with your own hands and detailed step-by-step instructions for installation and configuration. The system can be easily moved from one place to another without having to configure it again.

3. Ecological compatibility. This is a real "green technology" built on a renewable source of solar energy that does not pollute the environment.

4. Saving money. An Autonomous video surveillance system does not waste electricity, but generates it itself, stores it in the battery and is completely non-volatile, which means that it does not require any additional costs.

5. Long service life. Most solar panel manufacturers offer a 25-year warranty. After the warranty period expires, the solar panel can still produce at least $80 \%$ of its life.

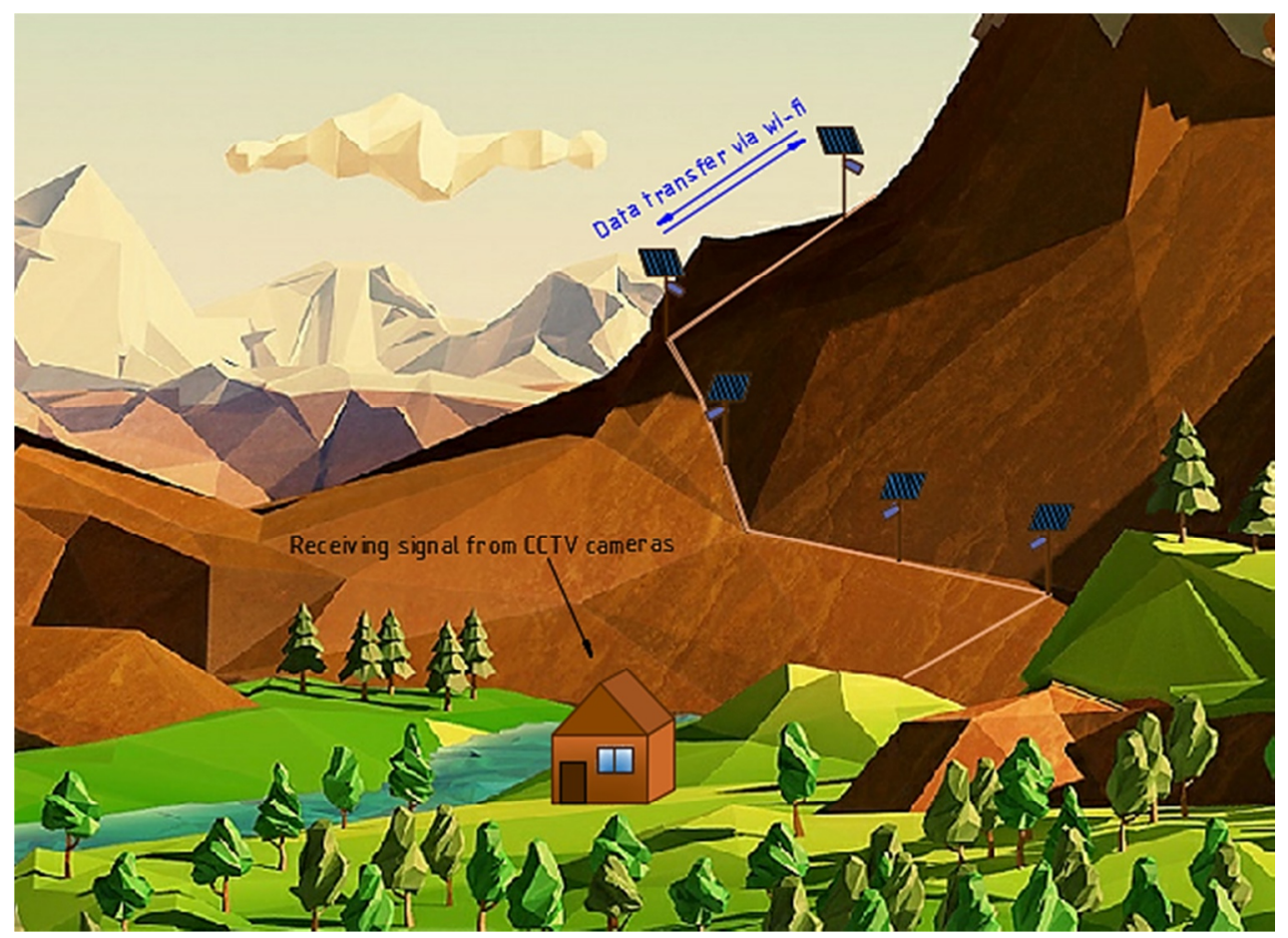

Fig. 2. Wireless communication on the ground.

Scope of these systems:

Video surveillance systems that use alternative energy sources can be used everywhere, but they are most relevant in such areas:

- on construction sites;

- in agricultural infrastructure;

- $\quad$ at industrial enterprises;

- in forested areas of the city;

- in places of rest of citizens;

- on motorways;

- along the railway;

- on specially protected sites; 
- $\quad$ at concert venues and stadiums;

- $\quad$ along main pipelines and other facilities.

\section{Advantages}

It does not require connection to the electrical network and cable laying. They are installed in any place and allow you to organize video monitoring of geographically distributed and hard-to-reach objects. It is not possible to turn off the video camera by cutting the electrical wires. They operate in automatic mode and do not require adjustment or maintenance. The powerful solar battery, high-capacity battery and multi-program controller ensure reliable operation. Simple installation that takes no more than 30 minutes. Low investment costs. Pay off when installed. Operating temperature range: -30 to $+50{ }^{\circ} \mathrm{C}$.

The installation of the Foundation:

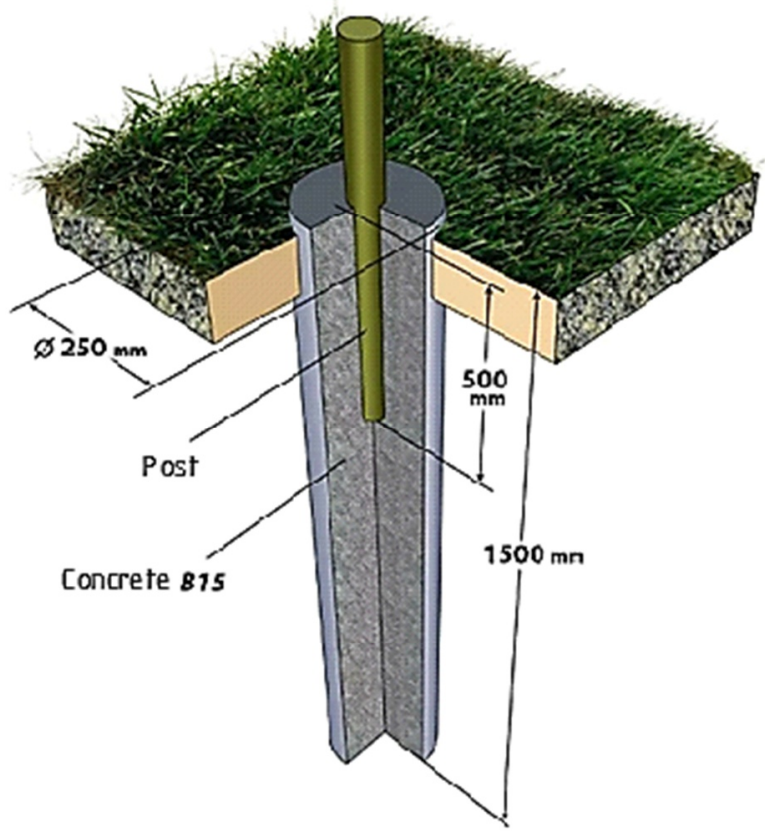

Fig. 3. The installation of the Foundation.

\subsection{Principle of operation}

The digital video camera is powered by a GM-150/150 solar-powered power plant. One Sunny day will be enough for the camera to work during 10 cloudy days. Power solar power sufficient to operate the system all year, even during extended cloudy weather in the "dark" season (December, January. The video camera captures an image on an object, on an event, or in constant mode and transmits it via the GSM channel to the Internet or Wi-Fi connection to the end user. If the network is down or temporarily unavailable, the camera records the image on the built-in SD card (optional), the contents of which can also be read remotely via the Internet. 


\subsection{Principle of operation}

The principle of operation of a solar-powered video camera is quite simple. The video camera is installed in place, so as to cover the required coverage area, while the installation site should not be heavily shaded, so as not to create problems in the operation of the solar battery. Next, the solar panel is installed (deployed) or mounted. The type of installation method is determined according to the design of the video camera: a video camera with built - in or remote solar panels. Very often, manufacturers deliver devices that are $100 \%$ ready for use. In this case, it is enough to install the video camera in the selected location and enable it (the "Plug \& Play" principle). If there is a receiving and transmitting unit and a spatial control system in the device, the operation is performed as follows: When the sensor is triggered or at a command from the Central console, the camera changes its spatial position, depending on the object of observation or the operator's command. The camera can send an alarm signal, if this function is available, with the transfer of images of the object that caused this mode of operation. For each model of such devices, the principle of operation in a specific situation is defined, which is described in detail in the" operating Instructions " of each model.

\subsection{How the solar battery works}

Solar cells are plates of silicon with a thickness of $0.3 \mathrm{~mm}$.boron is added to the plate on the side where the light falls. This leads to the appearance of an excessive number of free electrons. On the reverse side, phosphorus is added, which leads to the formation of "holes". The boundary between them is called a p-n junction. When light hits the plate, it" knocks out " the electrons on the opposite side. So there is a potential difference. Regardless of the size of the element, one cell develops a voltage of $0.7 \mathrm{~V}$. To increase the voltage, they are connected in series, and to increase the current - in parallel.

The maximum efficiency of the panel, and therefore the power, is achieved when the light falls at an angle of 90 degrees. In some stationary devices, the battery turns after the sun, but this greatly increases the cost and makes the structure heavier.

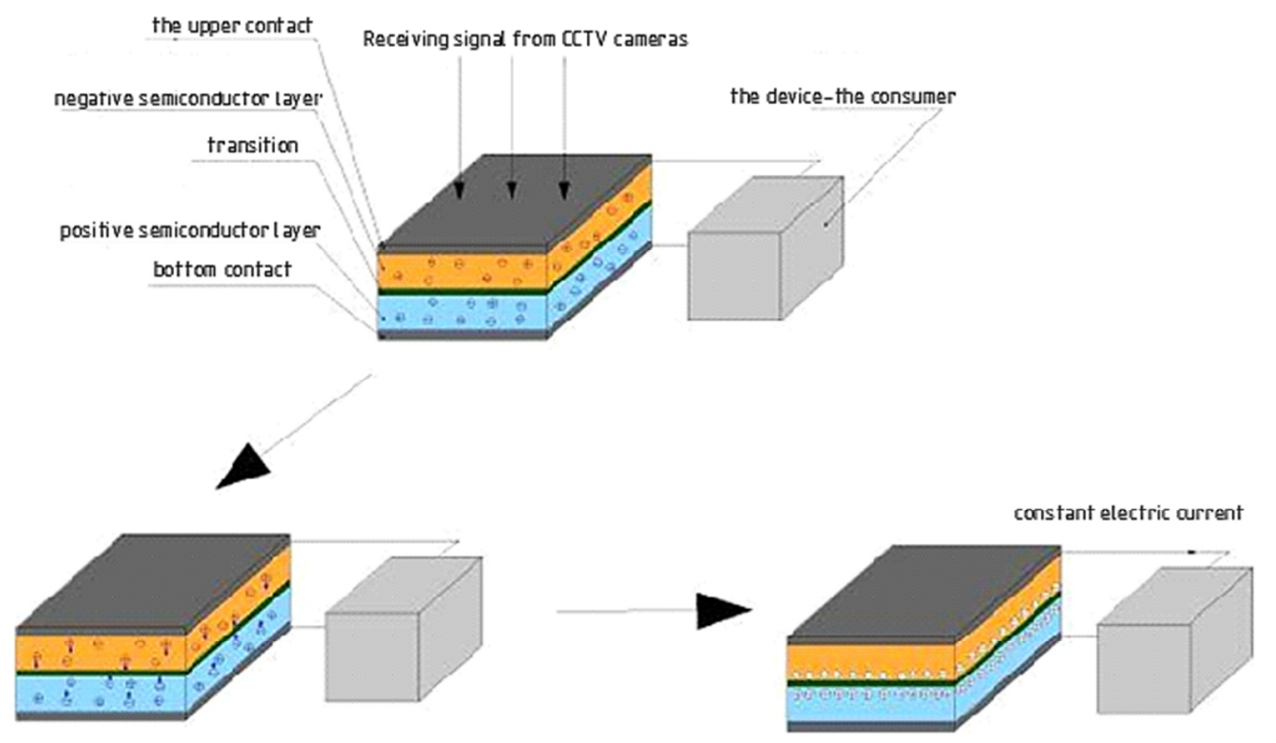

Fig. 4. The structure of the solar battery. 


\subsection{Impact of solar module production on the environment}

Any production is an interference with the primordial nature and thus is harmful. It is necessary to analyze the damage estimates that can cause this product to determine its profitability.

The main processes for the production of solar modules include: melting ingots, cutting plates, manufacturing solar cells and assembling the panels themselves.

Production of raw materials from which ingots are melted is polycrystalline silicon (polysilicon). It is widely used in electronics (semiconductors). This process is the most harmful of the production of solar cells.

\subsection{The principle of the technology}

From quartz, metallurgical silicon is obtained, and from it more pure polycrystalline silicon. In the process of converting metallurgical silicon into polycrystalline, a by-product of silicon tetrachloride is released, a non-flammable substance, but very harmful. The process involves the reaction of hydrochloric acid with metallurgical silicon to produce trichlorosilane. Trichlorosilane then reacts with hydrogen, resulting in polysilicon together with liquid silicon tetrachloride.

Currently, all countries that produce polysilicon (China, USA, Norway, Germany, South Korea, etc.) have adopted standards, and these wastes are processed to produce more polysilicon.

Getting polysilicon from silicon tetrachloride requires less energy than extracting it from raw silicon dioxide, so recycling this waste is a fairly profitable enterprise. Today, polysilicon producers are switching to closed-cycle industrial processes, which provides a significant reduction in environmental impact.

Thus, there is a constant decrease in the specific environmental footprint in this industry. The watt produced today contains much less harm to the environment than it did before.

Advantages from the point of view of ecology.

- during operation, emissions of carcinogens, carbon monoxide and carbon dioxide to the environment are zero;

- quiet operation;

- possibility of recycling.

\subsection{Economic efficiency}

One of the main factors when using the source is the economic benefit. It directly depends on the power of the battery and the area of the photovoltaic cells that receive the rays. If you take a city like Moscow as an example, you can get the following interesting data. If the power of the device is $800 \mathrm{~W}$, it allows limited use of household appliances, but will not be able to provide uninterrupted electricity supply during the day for heating the premises.

The $13.5 \mathrm{~kW}$ device almost completely replaces electricity, which can provide constant heating of the house in all months of the year, except for November, December and January. In this case, you can leave the main devices to work from solar devices, and connect the heating to the Central system. So you can save a lot of money. The most powerful generators are those that have a power of $31.5 \mathrm{~kW}$. They will allow you to completely abandon the main types of energy supply and use only the energy of the sun throughout the year for a long time. But such devices are expensive, which limits their use. 


\subsection{Factors that affect the return on your investment in solar panels}

- Inflation will increase electricity tariffs from the grid every year.

Thus, when the price of electricity increases, the product pays back.

- The price of solar panels and their installation in the currency is gradually falling. According to Swanson's law: the cost of solar cells (photovoltaic cells) tends to decrease by $20 \%$ with each doubling of cumulative capacity.

Research has shown that the price of photovoltaic cells has fallen 100 times in almost 40 years. The data is shown in the graph.

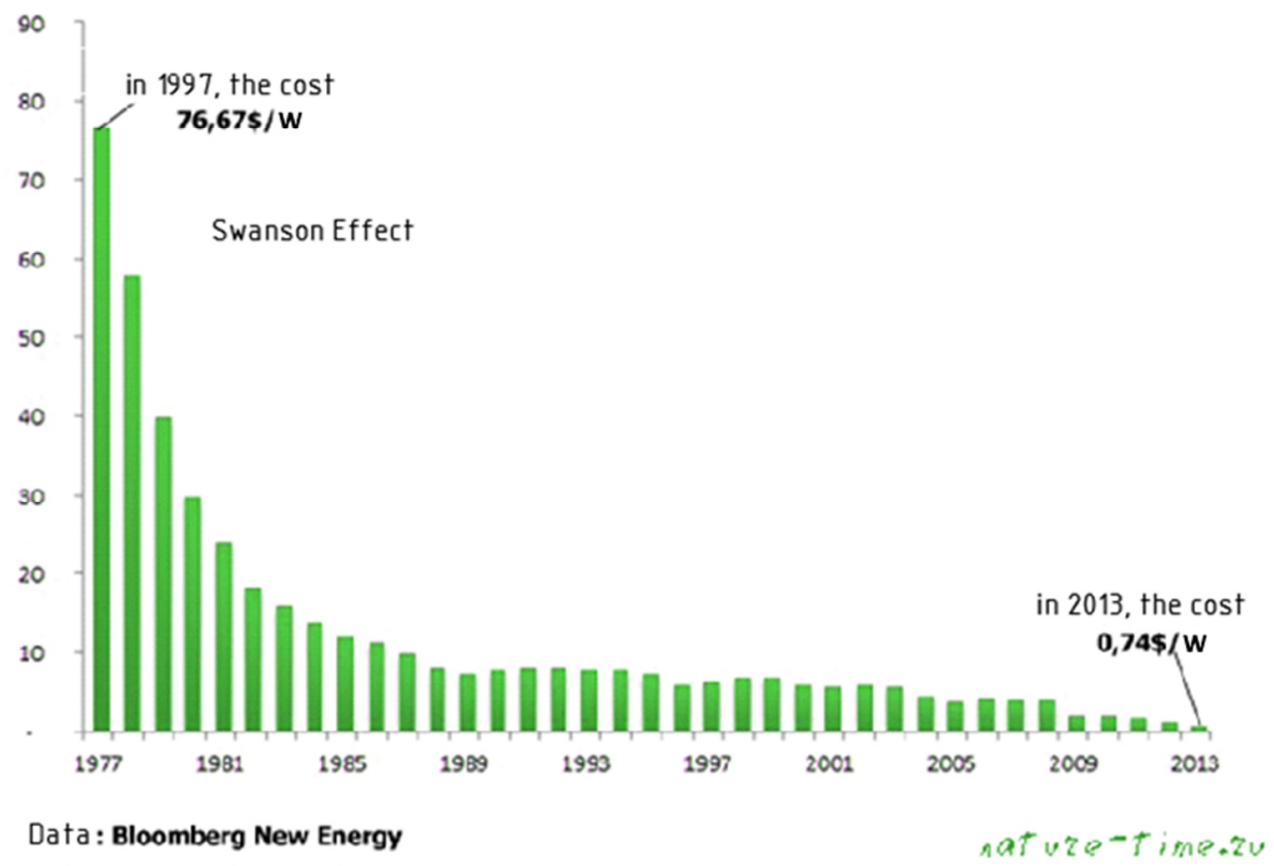

Fig. 5. Cost of photovoltaic cells $(\$ / V)$ (Source: nature-time.ru).

\section{Conclusion}

The sun, as a source of energy, can be used anywhere in the world and in any area. The sun is an innovative alternative source of electricity. Its use in the construction of buildings and structures solves many problems related to the issue of providing the object with electricity. Solar energy is the most affordable and cost-effective. The article proposed one of the options for using solar energy, namely, video surveillance and solar-powered lighting poles, which can be used in a variety of human activities. They are easy to install, operate, and do not require additional power grids to be connected to them. The use of solar panels can solve a complex of installation, economic and environmental problems.

\section{References}

1. P.R. Sabadi, Sunny house (Stroizdat, Moscow, 1981)

2. N.V. Kharchenko, Individual solar installations (Energoatomizdat, Moscow, 1991)

3. A.J. Globerman, A.K. Zaitsev, Silicon solar panels (State energy publishing house, 
Moscow-Leningrad, 1961)

4. F.A. Dyakov, Small power engineering of Russia: problems and prospects (Energoprogress: Energetika, Moscow, 2003)

5. A.A. Khaziakhmetova, A.S. Subbotin, Geo-Ecological problems of the technogenic stage of the Earth's history. Ministry of science and higher education of the Russian Federation, national research Moscow state University of civil engineering, 94-99 (2019)

6. A.S. Subbotin, L.A. Prostatin, Construction 2, 24-25 (2019) 